\title{
Why all prostate cancer surgery should include an adequate lymph node dissection
}

\author{
D. Robert Siemens, MD, FRCSC
}

Can Urol Assoc J 2010;4(6):427-9

$\mathrm{T}$ he role of a lymph node dissection in most cancer sites portends a benefit from accurate staging and assignment of adjuvant therapy or, possibly, a direct therapeutic effect by local/regional control. The adequacy of this regional dissection has become an important quality of care indicator (i.e., colon, rectal, testes and bladder). The adoption of recommendations to limit lymphadenectomy in other sites has generally followed prospective studies (i.e., uterine) or established predictive tools (i.e., sentinel biopsy in melanoma, breast cancer). This issue is controversial for prostate cancer management given the lack of prospective data and ambiguous retrospective studies ${ }^{1}$ and is illustrated in the variation in our clinical practice guidelines (Table 1). ${ }^{2-5}$

Coincident with the decrease of lymph node involvement (LNI) in most prostatectomy series ${ }^{6,7}$ there has been remarkable decline in pelvic lymph node dissection (PLND) for low-risk disease, ${ }^{8}$ although this trend may be less apparent in Canada. ${ }^{9}$ A risk-adapted approach to PLND remains controversial; it has been suggested that other complicating elements are involved in its decline, including changes in surgical approach as well as reimbursement issues. ${ }^{10}$ But what is the evidence to abandon this concept of regional control for prostate cancer in patients with perceived lowrisk disease? Without prospective randomized data the argument to omit PLND generally revolves around the following three issues: staging, therapeutic benefit and side effects.

\section{Staging issues}

Recent mapping studies suggest that a limited PLND (involving only the superficial external iliac-obturator group) and an even more extended PLND will miss a significant number of lymph nodes with metastatic disease. ${ }^{11}$ Debate exists on the optimal extent or location of PLND, but it is likely that there is a threshold for the number of nodes (approximately 20) to ensure a representative sampling. ${ }^{12-14}$ However, PLND still represents the most accurate and reliable staging procedure for the detection of $\mathrm{LNI}$ in prostate cancer. Despite numerous technical advances, including positron emission tomography/ computed tomography, lymphotropic nanoparticle-enhanced magnetic resonance imaging and sentinel lymphoscintigraphy, standard lymph node imaging lacks sufficient sensitivity to supplant PLND. ${ }^{1}$

The most common argument to omit PLND at prostatectomy is that prediction of LNI can be determined with preoperative parameters with the aid of prediction models. Multiple prediction tables or nomograms have been published with significant variation in their predictive accuracy. ${ }^{15-18}$ Two commonly used tools, an update of the Partin tables ${ }^{15}$ and the preoperative nomogram by Cagiannos and colleagues, ${ }^{16}$ reported accuracies of only $76 \%$ in validation studies. Furthermore, most of these tools were developed in populations with only a limited PLND (with $\mathrm{LNI}<1 \%$ ) $^{19,20}$ and therefore seriously underestimated the true presence of LNI. Recent series of more extended PLND reveal alarmingly higher rates of LNI including one cohort of patients with a $\mathrm{PSA}<10$ having a $\mathrm{LNI}$ of $11 \% .{ }^{21}$ Other extended PLND series in low-risk patients have confirmed LNI rates up to $7.4 \%{ }^{22,23}$ This issue is critical to our understanding and subsequent reliance of predictive tools in the surgical management of prostate cancer.

\section{Therapeutic issues}

The putative reasoning for accurate staging in prostate cancer is to appropriately assign patients for adjuvant therapy. Despite some debate to its applicability, there is prospective, randomized evidence for the early addition of androgen deprivation therapy for men with lymph node positive disease. ${ }^{24}$ Such adjuvant treatment may affect epithelial-stromal interactions sufficiently to arrest the growth of micrometastases into clinically apparent lesions..$^{25}$ Still, the overall impact of PLND on cancer outcomes remains controversial given the lack of prospective data. However, there is a growing body of evidence that PLND may have a direct therapeutic benefit. The long-term outcomes of patients with low burden lymph node metastasis are exceptional, regardless of the administration of adjuvant treatments. ${ }^{26-28}$ Reports of 10 -year cause-specific survival are as high as $85.8 \%{ }^{27}$ for men with positive lymph nodes and as high as $94 \%$ for those with very low volume nodal disease. ${ }^{28}$ Several studies have demonstrated a survival benefit for men treated surgically with PLND compared to ADT alone. ${ }^{29-31}$ 


\begin{tabular}{lll}
\hline $\begin{array}{l}\text { Table 1. Overview of clinical practice guidelines on prostate } \\
\text { cancer management }\end{array}$ & \multicolumn{1}{c}{$\begin{array}{c}\text { Risk adapted } \\
\text { recommendation } \\
\text { for PLND }\end{array}$} & $\begin{array}{c}\text { Extent of } \\
\text { PLND }\end{array}$ \\
\hline CCO & $\begin{array}{l}\text { High risk mandatory } \\
\text { Intermediate risk } \\
\text { recommended } \\
\text { Low risk optional }\end{array}$ & Standard \\
\hline EUA & $\begin{array}{l}\text { High risk and } \\
\text { intermediate risk }\end{array}$ & Extended \\
\hline AUA & $\begin{array}{l}\text { Reserved for higher } \\
\text { risk of LNI }\end{array}$ & Not indicated \\
\hline NCCN & $\begin{array}{l}\text { Exclude PLND if }<2 \% \\
\text { LNI }\end{array}$ & Extended \\
\hline PLND = pelvic lymph node dissection; LNI = lymph node involvement; CCO = Cancer Care \\
Ontario; EAU = European Association of Urology; AUA = American Urological Association; \\
NCCN = National Comprehensive Cancer Network
\end{tabular}

Furthermore, there is growing interest in the concept of "biologically" positive, pathologically negative lymph nodes and that removal of these nodes with micro-metastatic disease may lead to a therapeutic benefit. Studies have reported a significant inverse association between number of removed lymph nodes and PSA-free and causespecific survival in node-negative patients. ${ }^{9,26,32}$ In one of the largest studies, Joslyn and colleagues reported that for No patients, those that had greater than 10 nodes removed had a lower risk of prostate cancer death than those who did not undergo PLND. ${ }^{32}$ We have demonstrated a similar trend in a population-based study in Ontario men with low to intermediate risk disease, ${ }^{9}$ although there is a real possibility that these latter findings are influenced by a "Will Rogers Phenomenon" misclassification bias. However, the evidence would suggest that the presence of $\mathrm{LNI}$ in those with lower risk disease is much higher than we intuitively expect and it is possible that these are the very cases that would benefit from an adequate PLND.

\section{Side effects}

Performing a PLND at the time of prostatectomy does increase some time and side effects, with reported PLND specific complication rates in contemporary series varying between $2 \%$ and $35 \% .^{1,13,33-35}$ There is some controversy whether a more extended PLND leads to higher complication rates but in these series the higher rates are driven mostly on the development of lymphocoeles. ${ }^{35}$ Although PLND is not a completely innocuous procedure, the overall added complications to the prostatectomy itself is likely acceptable, with a low likelihood of serious complications extending hospital stay or long-term morbidity.

There is significant need, yet little likelihood, for a prospective randomized study to determine the appropriateness of a risk-adapted approach to omitting PLND at the time of prostatectomy. In the meantime, given the only modest accuracy of other prediction tools, the possibility of outcome benefits with PLND (especially for those with lower "risk" or volume of nodal disease) and the acceptable added morbidity, it remains essential that all men who truly need surgical treatment of their prostate cancer should also have a PLND. ${ }^{36}$

Associate Professor, Departments of Urology, Oncology, Anatomy and Cell Biology, Queen's University, Kingston, ON

Competing interests: None declared.

This paper has been peer-reviewed.

\section{References}

1. Briganti A, Blute ML, Eastham JH, et al. Pelvic lymph node dissection in prostate cancer. Eur Urol 2009;55:1251-65.

2. Chin JL, Srigley J, Mayhew LA, et al. Guideline for optimization of surgical and pathological quality performance for radical prostatectomy in prostate cancer management: evidentiary base. Can Urol Assoc J 2010;:13-25.

3. NCCN Clinical Practice Guidelines in Oncology. Prostate cancer. http://www.ncen.org/professionals/ physician_gls/PDF/prostate.pdf. Accessed November 17, 2010.

4. Thompson I, Thrasher JB, Aus $G$, et al. Guideline for the management of clinically localized prostate cancer: 2007 update. J Urol 2007;177:2106-31.

5. Heidenreich A, Aus G, Bolla M, et al. EAU guidelines on prostate cancer. Eur Urol 2008;53:68-80.

6. Palapattu GS, Allaf ME, Trock BJ, et al. Prostate specific antigen progression in men with lymph node metastases following radical prostatectomy: results of long-term followup. J Urol 2004;172:1860.

7. Daneshmand S, Quek ML, Stein JP, et al. Prognosis of patients with lymph node positive prostate cancer following radical prostatectomy: long-term results. J Urol 2004;172:2252.

8. Kawakami J, Meng MV, Sadetsky N, et al. Changing patterns of pelvic lymphadenectomy for prostate cancer: results from CaPSURE. I Urol 2006;176(4 Pt 1):1382-6.

9. Withrow DR, DeGroot JM, Siemens DR, et al. Therapeutic value of lymph node dissection at radical prostatectomy: a population-based case-cohort study. [epub ahead of print] BJU Int doi:10.1111/i.1464410X.2010.09805.x.

10. Hu JC, Prasad SM, Gu X, et al. Determinants of performing radical prostatectomy pelvic node dissection and the number of lymph nodes removed in elderly men. Urology doi:10.1016/j.urology.2010.05.015.

11. Mattei A, Fuechsel FG, Bhatta Dhar N, et al. The template of the primary lymphatic landing sites of the prostate should be revisited: results of a multimodality mapping study. Eur Urol 2008;53:118-25.

12. Heidenreich A, Varga Z, Von Knobloch R. Extended pelviclymphadenectomy in patients undergoing radical prostatectomy: high incidence of lymph node metastasis. J Urol 2002;167:1681-6.

13. Bader P, Burkhard FC, Markwalder R, et al. Is a limited lymph node dissection an adequate staging procedure for prostate cancer? J Urol 2002;168:514-8.

14. Weingartner K, Ramaswamy A, Bittinger A, et al. Anatomical basis for pelvic lymphadenectomy in prostate cancer: results of an autopsy study and implications for the clinic. J Urol 1996; 156:1969-71.

15. Makarov DV, Trock BJ, Humphreys EB, et al. Updated nomogram to predict pathologic stage of prostate cancer given prostate-specific antigen level, clinical stage, and biopsy Gleason score (Partin tables) based on cases from 2000 to 2005. Urology 2007;69:1095-101.

16. Cagiannos I, Karakiewicz P, Eastham JA, et al. A preoperative nomogram identifying decreased risk of positive pelvic lymph nodes in patients with prostate cancer. I Urol 2003;170:1798-803.

17. Briganti A, Chun FK-H, Salonia A, et al. Validation of a nomogram predicting the probability of lymph node invasion among patients undergoing radical prostatectomy and an extended pelvic lymphadenectomy. Eur Urol 2006;49:1019-26; discussion 26-7.

18. Karam JA, Svatek RS, Karakiewicz PI, et al. Use of preoperative plasma endoglin for prediction of lymph node metastasis in patients with clinically localized prostate cancer. Clin Cancer Res 2008;14:1418-22.

19. Allaf ME, Palapattu GS, Trock BJ, et al. Anatomical extent of lymph node dissection: impact on men with clinically localized prostate cancer. J Urol 2004;172:1840-4. 
20. Clark T, Parekh DJ, Cookson MS, et al. Randomized prospective evaluation of extended versus limited lymph node dissection in patients with clinically localized prostate cancer. J Urol 2003;169:145-7.

21. Schumacher $M C$, Burkhard FC, Thalmann $\mathrm{GN}$, et al. Is pelvic lymph node dissection necessary in patients with a serum PSA $<10 \mathrm{ng} / \mathrm{ml}$ undergoing radical prostatectomy for prostate cancer? Eur Urol 2006; $50: 272-9$

22. Weckermann D, Goppelt $M$, Dorn $R$, et al. Incidence of positive pelvic lymph nodes in patients with prostate cancer, a prostate-specific antigen (PSA) level of $<0 \mathrm{r}=10 \mathrm{ng} / \mathrm{mL}$ and biopsy Gleason score of $<0$ or $=6$, and their influence on PSA progression-free survival after radical prostatectomy. BJU Int 2006;97:1173-8.

23. Heidenreich A, Ohlmann CH, Polyakov S. Anatomical extent of pelvic lymphadenectomy in patients undergoing radical prostatectomy. Eur Urol 2007;52:29-37.

24. Messing EM, Manola J, Yao J, et al. Immediate versus deferred androgen deprivation treatment in patients with node- positive prostate cancer after radical prostatectomy and pelvic lymphadenectomy. Lancet Oncol 2006;7:472.

25. Sokoloff MH, Rinker-Schaeffer CW, Chung LWK, et al. Adjunctive therapy for men with high risk localized and locally advanced prostate cancer: targeting disseminated tumor cells. J Urol 2004; 172:2539.

26. Masterson TA, Bianco FJ Jr, Vickers AJ, et al. The association between total and positive lymph node counts, and disease progression in clinically localized prostate cancer. J Urol 2006;175:1320-4.

27. Booriian SA, Thompson RH, Siddiqui S, et al. Long-term outcome after radical prostatectomy for patients with lymph node positive prostate cancer in the prostate specific antigen era. J Urol 2007;178:864-70.

28. Cheng L, Zincke H, Blute ML, et al. Risk of prostate carcinoma death in patients with lymph node metastasis. Cancer 2001;91:66.
29. Cadeddu JA, Partin AW, Epstein Jl, et al. Stage DI (Tl-3, N1-3, MO) prostate cancer: a case-controlled comparison of conservative treatment versus radical prostatectomy. Urology 1997;50:251.

30. Ghavamian R, Bergstralh EJ, Blute ML, et al. Radical retropubic prostatectomy plus orchiectomy versus orchiectomy alone for pTxN+ prostate cancer: a matched comparison. J Urol 1999;161:1223.

31. Grimm MO, Kamphausen S, Hugenschmidt H, et al. Clinical outcome of patients with lymph node positive prostate cancer after radical prostatectomy versus androgen deprivation. Eur Urol 2002;41:628.

32. Joslyn SA, Konety BR. Impact of extent of lymphadenectomy on survival after radical prostatectomy for prostate cancer. Urology 2006;68:121-5.

33. Clark T, Parekh DJ, Cookson MS, et al. Randomized prospective evaluation of extended versus limited lymph node dissection in patients with clinically localized prostate cancer. I Urol 2003;169:145-7.

34. Stone NN, Stock R, Unger P. Laparoscopic pelvic lymph node dissection for prostate cancer: comparison of the extended and modified technique. J Urol 1997;158:1891-4.

35. Briganti A, Chun FK, Salonia A, et al. Complications and other surgical outcomes associated with extended pelvic lymphadenectomy in men with localized prostate cancer. Eur Urol 2006;50:1006-13.

36. Burkhard FC, Schumacher MC, Studer UE. An extended pelvic lymph-node dissection should be performed in most patients if radical prostatectomy is truly indicated. Nat Clin Pract Urol 2006;3:454-5.

Correspondence: Dr. D. Robert Siemens, 76 Stuart Street, Kingston ON K7L 2V7; siemensı@ kgh.kari.net 